www.jmscr.igmpublication.org

Index Copernicus Value: 79.54

ISSN (e)-2347-176x ISSN (p) 2455-0450

crossref DOI: https://dx.doi.org/10.18535/jmscr/v7i4.100

\title{
Dietary and Clinical Profile of Patients with Non-alcoholic Steatohepatitis
} (NASH)

\author{
Authors \\ Dr Vinod Kumar ${ }^{1}$, Dr Ritu Bhagat ${ }^{2^{*}}$ \\ ${ }^{1}$ Consultant Physician, JK Health Services \\ ${ }^{2}$ Senior Resident Department of Pathology, GMC Jammu, JK India \\ *Corresponding Author \\ Dr Ritu Bhagat \\ R/O Bandhu Rakh Kunjwani, Jammu (J\&K) Pin 180010, India \\ Email:drvkatil76@gmail.com, Mobile919419965435
}

\begin{abstract}
Introduction: The term NASH was coined by Ludwig et al. NASH stands for non-alcoholic steatohepatitis which is included in the spectrum of NAFLD which ranges from steatosis, steatohepatitis, fibrosis, cirrhosis and complications.

Aim: The objective is to study the dietary, clinical and other risk factors associated with NASH.

Materials and Methods: The present study was carried out on 60 patients of NASH over a period of six months in 2010 at Department of Medicine GMC, Jammu. All patients with NASH were screened for various risk factors associated with NASH. Detailed history was taken and thorough clinical examination was done.
\end{abstract}

Results: out of 60 patients, 28(46.66\%) were males and 32(53.32\%) were females. $85 \%$ of the patients were in the age group of 31-70 years.

Conclusion: In our study $73.33 \%$ (44/60) of patients were found to be non-vegetarian and $26.6 \%$ $(16 / 60)$ of patients were found to be asymptomatic. Right subcostal discomfort was the most common reported symptom (69.33\%).

Keywords: alanine transaminase, alkaline phosphatase, non-alcoholic steatohepatitis, right subcostal discomfort.

\section{Introduction}

Non-alcoholic fatty liver disease (NAFLD) is an increasingly recognised condition that may progress to end stage liver disease. Non-alcoholic fatty liver disease refers to wide spectrum of liver damage ranging from simple steatosis to steatohepatitis, advanced fibrosis and cirrhosis. Steatohepatitis represents only a stage within the spectrum of non-alcoholic fatty liver disease ${ }^{[1]}$. Ludwig et al introduced term nonalcoholic steatohepatititis to describe liver disease that is histologically indistinguishable from alcoholic hepatitis but occurs in persons who do not consume excess alcohol ${ }^{[2]}$. NAFLD is defined as fat accumulation in liver exceeding $5 \%$ to $10 \%$ by weight. Inherent to defining NAFLD and NASH 
is threshold at which steatohepatitis become alcohol related. Many centers accepts upper limit of 20-40 gm/day in men and $20 \mathrm{gm} /$ day in women $^{[3]}$. NAFLD is found in $70 \%$ of obese and $35 \%$ of lean patients. NASH is found in $18.5 \%$ of obese and $2.7 \%$ of lean patients. There is even distribution of NASH among men and women.

\section{Materials and Methods}

The present work is a hospital based crosssectional study that included 60 patients of NASH registered with GMC, Jammu for a period of six months. All patients with NASH were screened for various risk factors associated with NASH. Detailed history was taken and thorough clinical examination was done. Required investigations were done such as HB, TLC, DLC, Blood sugar, Renal function tests, Complete liver tests, Serum lipid profile, Viral markers (HBs Ag and Anti $\mathrm{HCV}$ ) and ANA were done. Ultrasound abdomen for hepatobiliary system was done to diagnose the patients of NASH.

\section{Inclusion Criteria}

1. Ultrasonographically proved fatty liver

2. Deranged liver function tests

3. No significant alcohol intake i.e. $<20 \mathrm{gm} /$ day

4. Absence of other relevant liver disease.

\section{Exclusion Criteria}

1. Daily alcohol intake i.e. $>20 \mathrm{gm} /$ day

2. Use of amiodarone, steroids, tamoxifen, methotrexate or high dose estrogen

3. Jejunal bypass or extensive small bowel resection

4. Other known liver disease

5. Malignancy.

\section{Results}

The present in hospital study entiled "Dietary and Clinical profile with non-alcoholic steatohepatitis (NASH)" was undertaken in GMC Jammu, in 60 patients who satisfied the inclusion criteria. Various findings were recorded and parameters calculated as per need and these were further correlated with each other as well.

Table 1: Age and Sex distribution

\begin{tabular}{|c|c|c|c|c|c|c|}
\hline \multirow[t]{2}{*}{ Age group in years } & \multicolumn{2}{|r|}{ Males } & \multicolumn{2}{|r|}{ Females } & & \multirow{2}{*}{$\begin{array}{l}\text { Total } \\
\text { Percentage }\end{array}$} \\
\hline & No. & Percentage & No. & Percentage & No. & \\
\hline $10-30$ & 5 & 8.33 & 2 & 3.33 & 7 & 11.66 \\
\hline $31-50$ & 17 & 28.33 & 16 & 26.66 & 33 & 55.0 \\
\hline $51-70$ & 6 & 10.0 & 12 & 20.0 & 18 & 30.0 \\
\hline$>70$ & 0 & 0.0 & 2 & 3.33 & 2 & 3.33 \\
\hline Total & 28 & 46.66 & 32 & 53.32 & 60 & 100 \\
\hline
\end{tabular}

Out of 60 patients, 28 were males and 32 were females. Majority of patients were in the group of $31-50$ years $(55 \%)$ followed by that in $51-70$ years
$(30 \%)$. Thus, $85 \%$ of the patients were in the age of 31-70 years.

Table 2: Dietary profile

\begin{tabular}{|l|c|c|}
\hline \multirow{2}{*}{} & \multicolumn{2}{|c|}{ No. of Patients } \\
\cline { 2 - 3 } & Male & Female \\
\hline Vegetarian & $5(17.85 \%)$ & $11(34.37 \%)$ \\
\hline Non-vegetarian & $23(82.15 \%)$ & $21(65.63 \%)$ \\
\hline & $28(100 \%)$ & $32(100 \%)$ \\
\hline
\end{tabular}


Table 3: (a) Clinical Profile

\begin{tabular}{|l|l|c|}
\hline \multirow{2}{*}{ Symptoms } & \multicolumn{2}{|c|}{ No. of Patients } \\
\cline { 2 - 3 } & Male & Female \\
\hline Asymptomatic & 10 & 6 \\
\hline Right subcostal discomfort & 16 & 22 \\
\hline Fatique & 13 & 19 \\
\hline Others & 8 & 16 \\
\hline Total * & & \\
\hline
\end{tabular}

The numbers don't add upto 60 since more than one signs and symptoms were present in single patient.

Table 3 (b): No. Of patients

\begin{tabular}{|l|c|c|}
\hline Clinical Sign & Males & Females \\
\hline Hepatomegaly & 28 & 32 \\
\hline Lipodystrophy & 4 & 6 \\
\hline Acanthosis nigricans & 3 & 4 \\
\hline Palmar Erythema & 1 & 2 \\
\hline Spleenomegaly & 2 & 1 \\
\hline Ascitis & 1 & 0 \\
\hline Pedal edema & 4 & 1 \\
\hline Total & & \\
\hline
\end{tabular}

*The numbers don't add upto 60 since more than one signs and symptoms were present in single patient.

\section{Discussion}

Present study was undertaken in 60 patients to assess the dietary and clinical profile of patients with non-alcoholic steatohepatitis. Out of which $28(46.66 \%)$ were males and $32(53.32 \%)$ were females. Maximum patients were in the age group of $31-50$ years $(55 \%)$ followed by that in $51-70$ years $(30 \%)$. Thus $85 \%$ of the patients in the age group of 31-70 years.

In our study $73.33 \%(44 / 60)$ of patients were found to be non-vegetarian. Mustafa et al. (2004) also concluded that non vegetarian diet and meat consumption were significantly associated with NAFLD.
In the present study $26.6 \%$ patients (16/60) were found to be asymptomatic. Right subcostal discomfort was the most common reported symptom. It was present in $69.33 \%(38 / 60)$ patients. Fatigue was the next more common symptom which was reported of $53.33 \%(32 / 60)$ patients. Chitturi et al (2000) in their study found that more of patients were asymptomatic or had minor symptoms (fatigue, epigastric discomfort, etc. ${ }^{[4]}$. Powell et al (1990) in his study found that $18 / 42$ had right upper quadrant pain ${ }^{[5]}$.

NASH (n=60)
\begin{tabular}{|l|c|c|}
\hline Variables & Mean & Range \\
\hline 1. Age (y) & 44 & $22-75$ \\
\hline 2. Sex female(\%) & $32 \%$ & \\
\hline 3. Anthropometric Data & & \\
\hline Obesity (\%) & $46 \%$ & \\
\hline Overweight (\%) & $39 \%$ & \\
\hline Lean (\%) & $15 \%$ & $56-110 \mathrm{~kg}$ \\
\hline 4. Body weight & $75.3 \mathrm{~kg}$ & $20.0-39.9$ \\
\hline 5. BMI & 29.18 & \\
\hline 6. Waist circumference & & \\
\hline Men $>102 \mathrm{~cm}$ & $10 / 28(35 \%)$ & \\
\hline Women $>88 \mathrm{~cm}$ & $25 / 32(78 \%)$ & $0.5-8.2$ \\
\hline 7. S.Bilirubin & 1.4 & $28-285$ \\
\hline 8. AST & 73.21 & \\
\hline
\end{tabular}




\begin{tabular}{|l|c|c|}
\hline 9.ALT & 102.35 & $33-240$ \\
\hline 10.Alk Po4. & 97.75 & $59-176$ \\
\hline 11.Glucose tolerance & & \\
\hline Diabetes Mellitus & $23 / 60(38.3 \%)$ & \\
Impaired Glucose Fasting & $14 / 60(23.3 \%)$ & \\
\hline 12.Hyperlipidemia & $30 / 60(50 \%)$ & \\
\hline
\end{tabular}

In the present study, it was found that obesity, hyperlipidemia and diabetes mellitus were significantly associated with the NASH.

In our study $46.6 \%(28 / 60)$ patients were found to be obese and $38.3 \%$ (23/60) were found to be overweight. Thus total of $84.9 \%$ (51/60) patients had $\mathrm{BMI}>25.9(15 \%)$ patients were found to have BMI $<25{ }^{[6]}$ Ludwig et al (1980) in his study found that $90 \%$ of patients with NASH were obese whereas ${ }^{[7]}$ Lee in (1989) demonstrated in his study that $69 \%$ patients with NASH were obese. ${ }^{[8]}$ Bacon et al (1994) in their study that $39 \%$ patients of NASH were obese. ${ }^{[9]}$ Angulo et al (1999) found in their study that $60 \%$ of patients with NASH were obese.

\section{Conclusion}

In our study it was found that NASH was more frequent among non-vegetarians and the patients who were vegetarian and suffering from NASH it was found that they consumed excess fats. Clinical profile was consistent with other studies and many patients were asymptomatic. Most common symptom was right subcostal discomfort followed by fatique.

\section{Bibliography}

1. Angulo P. Non-alcoholic fatty liver disease. NEJM 2002; 346:1221-31.

2. Caldwell SH, Oesler DH et al. cryptogenic cirrhosis. Clinical characterization and risk factors for underlying disease. Hepatology 1999; 29: 664-69.

3. Neuschwander Tetri BA et al. Nonalcoholic steatohepatitis: summary of an AASLD sigle topic conference. Hepatology 2003; 37:1202-19.
4. Chitturi et al. NASH and Insulin resistance: insulin hyper-secretion and specific association with insulin resistance syndrome. Hepatology 2002; 35:373-29.

5. Powell EE, Cooksley WGE et al. The natural history of non-alcoholic steatohepatitis: A follow up study of forty two patients for upto 21 years. Hepatology 1990; 11:74-80.

6. Ludwig J, Viggiano TR et al. Nonalcoholic steatohepatitis: mayo clinic experience with a hitherto unnamed disease. Mayo Clin Proc.1980; 55:434438.

7. Lee RG. Nonalcoholic steatohepatitis : A study of 49 patients. Hum Pathol 1989; 20:594-598.

8. Bacon BR, Faravash MJ et al. Nonalcoholic steatohepatitis : An expanded clinical entity. Gastroenterology 1994; 107: 1103-09.

9. Angulo P, Keach JC et al. Independent predictors of liver fibrosis in patients with non-alcoholic steatohepatitis. Hepatology 1999; 30:1356-62. 